\title{
Hespellia stercorisuis gen. nov., sp. nov. and Hespellia porcina sp. nov., isolated from swine manure storage pits
}

\author{
Terence R. Whitehead, ${ }^{1}$ Michael A. Cotta, ${ }^{1}$ Matthew D. Collins ${ }^{2}$ \\ and Paul A. Lawson ${ }^{2}$ \\ ${ }^{1}$ Fermentation Biotechnology Research Unit, National Center for Agricultural Utilization \\ Research, USDA, Agricultural Research Service, 1815 N. University Street, Peoria, \\ IL 61604, USA \\ ${ }^{2}$ School of Food Biosciences, University of Reading, Reading, RG6 6AP, UK
}

\begin{abstract}
Four Gram-positive-staining, strictly anaerobic, non-spore-forming, rod-shaped organisms were isolated from a pig manure storage pit. Comparative 16S rRNA gene sequence analysis revealed that the isolates belonged to two related but distinct groups. Sequence analysis showed that the two groups of isolates were highly related to each other (approx. $97 \% 16 \mathrm{~S}$ rRNA gene sequence similarity), forming a distinct cluster within the Clostridium coccoides suprageneric rDNA grouping. Biochemical and physiological studies confirmed the division of the isolates into two related, albeit distinct, groups. Based on both phenotypic and phylogenetic evidence, it is proposed that the unidentified rod-shaped isolates from pig manure should be classified in a novel genus, Hespellia gen. nov., as Hespellia stercorisuis sp. nov. and Hespellia porcina sp. nov. The type species of the novel genus is $H$. stercorisuis (type strain, $P C 18^{\top}=$ NRRL $\mathrm{B}-23456^{\top}=$ CCUG $46279^{\top}=$ ATCC BAA $-677^{\top}$ ) and the type strain of $\mathrm{H}$. porcina is PC $80^{\top}$ $\left(=\right.$ NRRL B- $23458^{\top}=$ ATCC BAA- $\left.674^{\top}\right)$.
\end{abstract}

\section{INTRODUCTION}

Intensive modern livestock-farming practices have resulted in the concentration of generated waste products into increasingly smaller locations. Lagoon treatment or deeppit storage are among the more favoured methods that are used to handle liquid swine manure. Storage of swine manure is associated with the production of a variety of odorous chemicals, many of which are due to the incomplete digestion processes that are associated with anaerobic systems (Yasuhara \& Fuwa, 1979; Spoelstra, 1980; Yasuhara et al., 1984; Zahn et al., 1997). In addition, production of gaseous emissions (such as ammonia) within confined facilities, such as those used with swine, can pose potential health problems to both animals and human workers. Although production of these chemicals is the result of microbiological activity, little is known about the types of micro-organisms that are responsible for their production. During the course of an ongoing study into the microbial

Published online ahead of print on 1 August 2003 as DOI 10.1099/ ijs.0.02719-0.

Abbreviations: ALD, aldehyde; DMA, dimethylacetal; FA, fatty acid; NRRL, Northern Regional Research Laboratory.

The GenBank/EMBL/DDBJ accession numbers for the 16S rRNA gene sequences of strains NRRL B-23456 ${ }^{\top}$ and NRRL B-23458 ${ }^{\top}$ are AF445264 and AF445239, respectively. diversity that is present within manure storage pits (Whitehead \& Cotta, 2000; Cotta et al., 2003), we characterized four strictly anaerobic, Gram-positive, asporogenous, rod-shaped organisms of uncertain taxonomic position. Based on the results of a polyphasic taxonomic study, it is proposed that the isolates should be assigned to a novel genus, Hespellia gen. nov., as Hespellia stercorisuis sp. nov. and Hespellia porcina sp. nov.

\section{METHODS}

Isolates $\mathrm{PC} 17, \mathrm{PC} 18^{\mathrm{T}}, \mathrm{PC} 80^{\mathrm{T}}$ and $\mathrm{PC} 82$ were recovered from a manure storage pit from a swine facility near Peoria, IL, USA, where feeder pigs were fed a corn/soybean-based diet. Samples (50$100 \mathrm{ml}$ ) from manure storage pits were collected by using a tank sampler and transferred to Whirl-Pak sampling bags (both from NASCO). Samples were kept on ice until they were returned to the laboratory. Isolations and enumerations were performed by plating samples that were diluted serially in anaerobic buffer onto habitatsimulating media, which contained either $40 \%(\mathrm{v} / \mathrm{v})$ substratedepleted rumen fluid (RF medium) (Dehority \& Grubb, 1976; Leedle \& Hespell, 1980) or $80 \%(\mathrm{v} / \mathrm{v})$ clarified swine manure slurry (Slurry medium; $8000 \mathrm{~g}, 20 \mathrm{~min}, 4{ }^{\circ} \mathrm{C}$ ) (Cotta et al., 2003). Media used in these experiments were prepared anaerobically by using the method of Hungate, as modified by Bryant (1972). Basic media contained macro- and microminerals, buffers, reducing agents and other components, as in RGM medium described by Hespell et al. (1987) or anaerobic BHI medium as described by Whitehead \& Flint (1995). No additional volatile fatty acids (FAs) were added to 
slurry-containing media. Glucose, xylose, cellobiose, maltose, starch (each at $0.05 \%, \mathrm{w} / \mathrm{v})$ and peptone $(0.3 \%, \mathrm{w} / \mathrm{v})$ were provided as complex carbon, nitrogen and energy sources. In the case of isolates $\mathrm{PC}^{\mathrm{T}}{ }^{\mathrm{T}}$ and $\mathrm{PC} 82$, agar medium contained $10 \mu \mathrm{g}$ erythromycin $\mathrm{ml}^{-1}$ (Cotta et al., 2003). Plates were incubated anaerobically in a Coy anaerobic chamber in a carbon dioxide/hydrogen (96:4) atmosphere. Plates were incubated initially at room temperature (approx. $24^{\circ} \mathrm{C}$ ) for manure slurry samples, to simulate the pit environment (Cotta et al., 2003). The new isolates were found subsequently to grow equally well at $37^{\circ} \mathrm{C}$. Single colonies were picked and streaked out repeatedly until pure cultures were obtained. For morphological and physiological studies, strains were grown on RGM medium with $0 \cdot 2 \%$ carbohydrate or BHI medium. Presence of spores was determined by visual examination, as well as by incubation of cultures in $95 \%$ ethanol followed by plating onto anaerobic agar medium. Fermentation end products were determined by using GC and HPLC; GC, including hydrogen production analyses, was performed on a Hewlett Packard model 5890A gas chromatograph with a HP Innowax capillary column $(30 \mathrm{~m} \times 0.32 \mathrm{~mm}, 0.5 \mu \mathrm{m}$ film thickness; Agilent Technologies) (Miller, 2001). HPLC detection of organic acids was performed by using a Bio-Rad Aminex HPX-87H column at $65{ }^{\circ} \mathrm{C}$ with $5 \mathrm{mM} \mathrm{H}_{2} \mathrm{SO}_{4}$ as solvent. Peaks were detected by a Waters model 410 differential refractometer and identified by comparison with retention times of authentic standards (Miller, 2001). For long-chain cellular FA analyses, isolates were grown in brain heart infusion broth. FAs were identified by using the MIDI system according to the manufacturer's instructions. Determination of DNA $\mathrm{G}+\mathrm{C}$ content was carried out by thermal denaturation of chromosomal DNA, using a Beckman model DU 640 spectrophotometer equipped with a high-performance temperature controller and $T_{\mathrm{m}}$ analysis software (Johnson, 1994). 16S rRNA gene fragments were generated by PCR with universal primers pA (positions 8-28, Escherichia coli numbering) and $\mathrm{pH}^{\star}(1542-1522)$. Amplified products were purified by using a QIAquick PCR Purification kit (Qiagen) and sequenced directly by using primers to conserved regions of the $16 \mathrm{~S}$ rRNA gene. Sequencing was performed by using a PRISM Taq Dyedeoxy Terminator Cycle Sequencing kit and a model 373A automatic DNA sequencer (both from Applied Biosystems). To establish the closest relatives of the isolates, preliminary searches in GenBank/EMBL were performed with the program FASTA. Closely related sequences were retrieved and aligned with the newly determined sequences by using the program DNATools (Rasmussen, 1995). Approximately 100 bases at the 5' end of the resulting multiple sequence alignment were omitted from further analysis because of alignment uncertainties (due to the highly variable region V1) by using the program GeneDoc (Nicholas et al., 1997). A phylogenetic tree was reconstructed according to the neighbour-joining method (Saitou \& Nei, 1987) with the programs DNATools and TREEVIEW (Page, 1996); stability of the groupings was estimated by bootstrap analysis (1000 replications).

\section{RESULTS AND DISCUSSION}

The four isolates that originated from pig manure slurries consisted of obligately anaerobic, non-motile, Grampositive rods with no visible spores. After $48 \mathrm{~h}$ anaerobic incubation at $37^{\circ} \mathrm{C}$ under an $\mathrm{N}_{2} / \mathrm{CO}_{2}(80: 20, \mathrm{v} / \mathrm{v})$ gas phase, colonies were non-haemolytic, grey, convex, smooth, shiny and translucent. All strains grew on bile/aesculin agar, producing black colonies, and all were catalasenegative. They produced hydrogen after growth on glucose, as determined by GC. Analysis of the end products of metabolism in BHI broth revealed formic $(16 \cdot 8-17 \cdot 1 \mathrm{mM})$, acetic $(13 \cdot 3-14 \cdot 1 \mathrm{mM})$, lactic $(9 \cdot 3-9 \cdot 9 \mathrm{mM})$ and propionic
$(3 \cdot 1-3 \cdot 4 \mathrm{mM})$ acids for strains PC17 and $\mathrm{PC} 18^{\mathrm{T}}$. Similar end-product profiles, which comprised formic $(23 \cdot 3-$ $24 \cdot 5 \mathrm{mM})$, acetic $(12 \cdot 1-23 \cdot 2 \mathrm{mM})$, lactic $(11 \cdot 3-17 \cdot 5 \mathrm{mM})$ and propionic $(2 \cdot 0-7 \cdot 5 \mathrm{mM})$ acids, were produced by strains $\mathrm{PC} 80^{\mathrm{T}}$ and $\mathrm{PC} 82$. None of the isolates reduced nitrate to nitrite and all were indole-negative. They hydrolysed aesculin and starch, but failed to hydrolyse gelatin. All four isolates utilized glucose, maltose, mannose, sucrose, fructose and xylose, but not raffinose, rhamnose or inulin, as carbon sources. In addition, isolates PC17 and PC18 ${ }^{\mathrm{T}}$ utilized lactose, cellobiose, trehalose, amygdalin and sorbitol, but failed to grow with arabinose or inositol. By contrast, isolates $\mathrm{PC}^{\mathrm{T}} 0^{\mathrm{T}}$ and $\mathrm{PC} 82$ utilized inositol and arabinose, but not lactose, cellobiose, amygdalin or sorbitol. The long-chain cellular FA profile of a representative isolate from each of the two biochemical types was determined. Both isolates $\left(\mathrm{PC} 18^{\mathrm{T}}\right.$ and $\left.\mathrm{PC}^{\mathrm{T}} 0^{\mathrm{T}}\right)$ displayed very similar patterns that consisted of complex mixtures of FAs, dimethylacetals (DMAs) and aldehydes (ALDs), with $\mathrm{C}_{14: 0} \mathrm{FA}, \mathrm{C}_{16: 0} \mathrm{FA}$ and $\mathrm{C}_{16: 1}$ 9cis DMA present in high amounts (Table 1). The DNA G $+\mathrm{C}$ contents of isolates $\mathrm{PC} 18^{\mathrm{T}}$ and $\mathrm{PC} 80^{\mathrm{T}}$ were found to be $43 \cdot 7$ and $43 \cdot 8 \mathrm{~mol} \%$, respectively. Both sets of chemical data reinforced the affinity between the isolates.

To determine the phylogenetic affinity between the isolates and to other species, their $16 \mathrm{~S}$ rRNA gene sequences were amplified by PCR and sequenced, yielding a continuous stretch of $>1450$ bases. The four isolates formed two groups on the basis of $16 \mathrm{~S}$ rRNA gene sequence similarity. Strains $\mathrm{PC} 17$ and $\mathrm{PC} 18^{\mathrm{T}}$ were found to be genetically highly related

Table 1. Cellular fatty acid compositions (\%) of Hespellia stercorisuis NRRL B-23456 ${ }^{\top}$ and Hespellia porcina NRRL $\mathrm{B}-23458^{\top}$

\begin{tabular}{|lcc|}
\hline Component & H. stercorisuis & H. porcina \\
\hline $\mathrm{C}_{12: 0}$ FA & $0 \cdot 5$ & $2 \cdot 5$ \\
$\mathrm{C}_{11: 0}$ DMA & $0 \cdot 5$ & $1 \cdot 0$ \\
$\mathrm{C}_{14: 0}$ FA & $15 \cdot 0$ & $22 \cdot 0$ \\
$\mathrm{C}_{14: 1}$ cis7 DMA & $1 \cdot 0$ & $2 \cdot 5$ \\
$\mathrm{C}_{14: 0}$ DMA & $3 \cdot 5$ & $11 \cdot 0$ \\
$\mathrm{C}_{16: 0}$ ALD & $1 \cdot 5$ & $1 \cdot 5$ \\
$\mathrm{C}_{15: 0} \mathrm{FA}$ & $1 \cdot 0$ & $0 \cdot 5$ \\
$\mathrm{C}_{16: 1}$ cis 9 FA & $3 \cdot 0$ & $2 \cdot 5$ \\
$\mathrm{C}_{16: 0}$ FA & $27 \cdot 5$ & $20 \cdot 0$ \\
$\mathrm{C}_{16: 1}$ cis 9 DMA & $18 \cdot 0$ & $11 \cdot 0$ \\
$\mathrm{C}_{16: 0}$ DMA & $6 \cdot 0$ & $7 \cdot 0$ \\
$\mathrm{C}_{18: 0}$ ALD & $0 \cdot 5$ & - \\
$\mathrm{C}_{17: 0}$ FA & $0 \cdot 5$ & $0 \cdot 5$ \\
$\mathrm{C}_{18: 1}$ DMA & $0 \cdot 5$ & - \\
$\mathrm{C}_{18: 1}$ cis 9 FA & $0 \cdot 5$ & $3 \cdot 5$ \\
$\mathrm{C}_{18: 0} \mathrm{FA}$ & $0 \cdot 5$ & $6 \cdot 0$ \\
$\mathrm{C}_{18: 1}$ cis 9 DMA & $0 \cdot 5$ & $1 \cdot 5$ \\
$\mathrm{C}_{18: 1}$ cis 11 DMA & $14 \cdot 5$ & $2 \cdot 5$ \\
$\mathrm{C}_{18: 0}$ DMA & $0 \cdot 5$ & $0 \cdot 5$ \\
\hline
\end{tabular}


to each other, displaying $100 \% 16 \mathrm{~S}$ rRNA gene sequence similarity, as did isolates $\mathrm{PC} 80^{\mathrm{T}}$ and PC82. However, $3 \%$ 16S rRNA gene sequence divergence was shown between the two groups. Sequence searches of GenBank/EMBL revealed that the unidentified isolates were members of the low-G + C Clostridium subphylum of Gram-positive bacteria. Treeing analysis revealed that the isolates were members of the Clostridium coccoides rDNA cluster. The phylogenetic position of the two groups of isolates (represented by strains $\mathrm{PC} 18^{\mathrm{T}}$ and $\mathrm{PC} 80^{\mathrm{T}}$ ) within the C. coccoides grouping is shown in Fig. 1.

It is evident from both phenotypic and comparative $16 \mathrm{~S}$ rRNA gene sequencing analysis that the anaerobic, Grampositive, rod-shaped isolates that were recovered from pig manure fall into two taxonomically distinct groups. Phylogenetically, the unidentified isolates are members of the C. coccoides group (rDNA cluster XIVa; Collins et al., 1994), a large suprageneric cluster that embraces taxa with a variety of generic names, such as Anaerostipes, Butyrivibrio, Catonella, Clostridium, Coprococcus, Dorea, Eubacterium, Johnsonella, Lachnospira, Roseburia, Ruminococcus and Sporobacterium. Within this suprageneric rDNA group, the two pairs of isolates formed a distinct and robust subcluster that was supported by a bootstrap value of $100 \%$ (Fig. 1). Based on both sequence divergence and tree topology considerations, it is clear that the unidentified isolates do not possess a particularly close association with any described species. The nearest apparent relative to the new isolates corresponds to an rDNA clone (designated OTU-95; 1453 bases) that was derived from an uncultured organism from the gastrointestinal tract of pigs (Leser et al., 2002). However, $6 \cdot 1-6 \cdot 4 \%$ sequence divergence between the pig manure isolates and this uncultured organism and the low bootstrap resampling value (Fig. 1) indicate that this association is not particularly close. Leser et al. (2002) published a comprehensive rDNA inventory of the pig gastrointestinal tract and described over 300 novel phylotypes, which may correspond to as-yet-uncharacterized bacterial genera or species. Surprisingly, none of these novel lines corresponded to either of the two groups of isolates reported here. Taxonomically, it is evident that the two groups of unknown isolates represent closely related, albeit different, species. 16S rRNA gene sequence divergence of $3 \%$ is consistent with separate species (Stackebrandt \& Goebel, 1994) and the two groups show major phenotypic differences. Before the advent of $16 \mathrm{~S}$ rRNA gene sequencing, the two swine manure species would have been considered taxonomically to conform to the genus Eubacterium, which has in the past acted as a repository for strictly anaerobic, Gram-positive, asporogenous, rodshaped organisms. However, it is now acknowledged universally that the eubacteria represent a phylogenetically very heterogeneous group of organisms and there is a growing consensus that the genus Eubacterium should be restricted to the type species Eubacterium limosum and its close phylogenetic relatives (Eubacterium barkeri, Eubacterium callanderi and Eubacterium aggregans) (Willems \& Collins, 1996; Kageyama et al., 1999). E. limosum and related species are far removed phylogenetically (approx. $20 \% 16 \mathrm{~S}$ rRNA gene sequence divergence) from the unidentified isolates reported here and belong to a different phylogenetic group (Collins et al., 1994; Willems \& Collins, 1996). Furthermore, the unknown isolates are incompatible phenotypically with eubacteria, as they do not produce butyrate as a major fermentation product. Based on phylogenetic findings, it is evident that the unidentified isolates form a distinct group and do not display a close affinity to any recognized genus within the C. coccoides rDNA cluster. The unknown organisms also

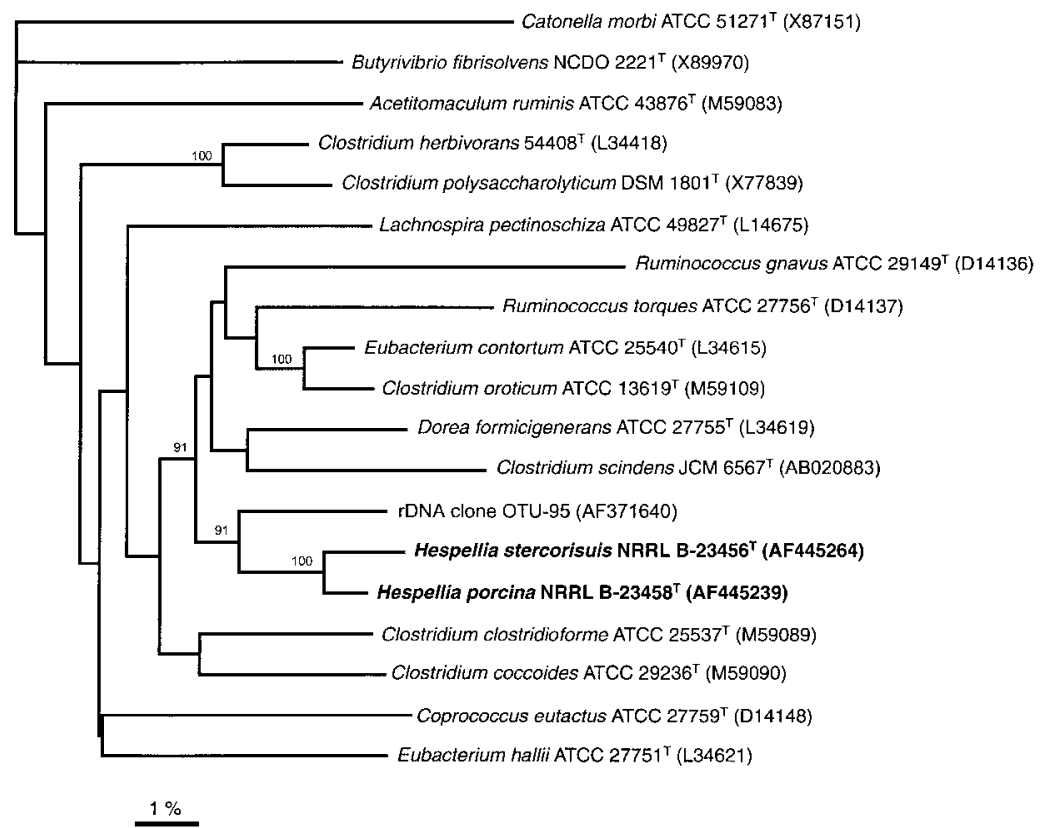

Fig. 1. Unrooted tree showing the phylogenetic relationships of $H$. stercorisuis and $H$. porcina amongst their nearest relatives within the C. coccoides rDNA grouping. The tree was constructed by using the neighbourjoining method and is based on a comparison of 1330 nt. Bootstrap values, each expressed as a percentage of 1000 replications, are given at branching points. 
differ phenotypically from all other genera within this suprageneric grouping. For example, they can be distinguished from clostridial species and other spore-forming taxa (e.g. Sporobacterium) in not producing endospores, from Lachnospira by the absence of curved cellular shapes, from Dorea by hydrolysis of starch and the end products of glucose metabolism, from Coprococcus and Ruminococcus by cellular morphology and the end products of glucose fermentation and from Roseburia and Butyrivibrio in the end products of glucose metabolism (i.e. not producing butyric acid) and in being non-motile. Based on their overall phenotypic and phylogenetic resemblance, combined with their distinctiveness from other members of the $C$. coccoides group, we consider that the two unidentified species merit classification in a novel genus, Hespellia gen. nov. We propose that isolates $\mathrm{PC} 17$ and $\mathrm{PC} 18^{\mathrm{T}}$ should be classified as Hespellia stercorisuis sp. nov. and isolates $\mathrm{PC}^{\mathrm{T}} 0^{\mathrm{T}}$ and PC82 should be designated Hespellia porcina sp. nov.

\section{Description of Hespellia gen. nov.}

Hespellia (Hes.pel'li.a. N.L. fem. n. Hespellia to honour the late American microbiologist Robert B. Hespell, in recognition of his many contributions to anaerobic microbiology).

Gram-positive-staining, non-spore-forming, non-motile, rod-shaped cells. Strictly anaerobic and catalase- and oxidase-negative. Glucose and some other sugars are fermented. Major end products of glucose metabolism are formic, acetic, lactic and propionic acids; hydrogen is produced. Butyric acid is not formed. Aesculin and starch are hydrolysed, but gelatin is not. Indole-negative. Nitrate is not reduced to nitrite. Long-chain cellular FAs consist of complex mixtures of FAs and DMAs, together with small amounts of ALDs. DNA G $+\mathrm{C}$ content is $43 \cdot 7-43 \cdot 8 \mathrm{~mol} \%$. The type species of the genus is Hespellia stercorisuis.

\section{Description of Hespellia stercorisuis sp. nov.}

Hespellia stercorisuis (ster.co.ri.su'is. L. masc. n. stercus, -oris faeces, manure; L. gen. n. suis of a pig, N.L. gen. n. stercorisuis from pig faeces/manure).

Cells consist of Gram-positive-staining rods that are obligately anaerobic, non-motile and non-spore-forming. Cells are $0 \cdot 5-1 \cdot 0 \mu \mathrm{m}$ wide by $1 \cdot 5-5 \cdot 0 \mu \mathrm{m}$ long and occur singly, in pairs or in short chains. After $48 \mathrm{~h}$ anaerobic incubation at $37^{\circ} \mathrm{C}$ under a gas phase of $\mathrm{N}_{2}$ and $\mathrm{CO}_{2}(80: 20, \mathrm{v} / \mathrm{v})$ on RGM/glucose agar, colonies are grey, convex, smooth, shiny and translucent. Catalase- and oxidase-negative. Hydrogen is formed after growth on glucose. End products of metabolism from BHI broth are formic, acetic, lactic and propionic acids. Glucose, lactose, cellobiose, trehalose, amygdalin, sorbitol, maltose, mannose, sucrose, fructose and xylose are utilized as energy sources, but arabinose, inositol, raffinose, rhamnose and inulin are not. Aesculin and starch are hydrolysed, but gelatin is not. Nitrate is not reduced. Indole is not produced. Long-chain cellular FAs consist of complex mixtures of FAs and DMAs, together with small amounts of ALDs; predominant components are $\mathrm{C}_{14: 0} \mathrm{FA}, \mathrm{C}_{16: 0} \mathrm{FA}, \mathrm{C}_{16: 1}$ cis $9 \mathrm{DMA}$ and $\mathrm{C}_{18: 1}$ cis 11 DMA. DNA G + C content of the type strain is $43.7 \mathrm{~mol} \%$.

The type strain is $\mathrm{PC} 18^{\mathrm{T}}=\mathrm{NRRL} \quad \mathrm{B}-23456^{\mathrm{T}}=\mathrm{CCUG}$ $46279^{\mathrm{T}}=$ ATCC BAA $-677^{\mathrm{T}}$. Isolated from pig manure.

\section{Description of Hespellia porcina sp. nov.}

Hespellia porcina (por.ci'na. L. fem. adj. porcina of pigs, pertaining to pigs).

Cells are Gram-positive-staining, non-motile, non-sporeforming rods. Obligately anaerobic. Cells are $0 \cdot 5-1 \cdot 0 \mu \mathrm{m}$ wide by $1 \cdot 5-4 \cdot 0 \mu \mathrm{m}$ long and occur singly, in pairs or in short chains. After $48 \mathrm{~h}$ anaerobic incubation at $37^{\circ} \mathrm{C}$ under a gas phase of $\mathrm{N}_{2}$ and $\mathrm{CO}_{2}(80: 20, \mathrm{v} / \mathrm{v})$ on RGM/ glucose agar, colonies are grey, convex, smooth, shiny and translucent. Catalase- and oxidase-negative. Hydrogen is formed after growth on glucose. End products of metabolism from BHI broth are formic, acetic, lactic and propionic acids. Glucose, arabinose, inositol, maltose, mannose, sucrose, fructose and xylose are utilized as energy sources, but amygdalin, cellobiose, lactose, raffinose, rhamnose, sorbitol, trehalose and inulin are not. Nitrate is not reduced. Aesculin and starch are hydrolysed, but gelatin is not. Indole is not produced. Long-chain cellular FAs consist of complex mixtures of FAs and DMAs, together with small amounts of ALDs; predominant components are $\mathrm{C}_{14: 0} \mathrm{FA}, \mathrm{C}_{14: 0}$ DMA, $\mathrm{C}_{16: 0} \mathrm{FA}$ and $\mathrm{C}_{16: 1}$ cis 9 DMA. DNA G $+C$ content of the type strain is $43 \cdot 8 \mathrm{~mol} \%$.

The type strain is $\mathrm{PC} 80^{\mathrm{T}}=$ NRRL B $-23458^{\mathrm{T}}=$ ATCC BAA$674^{\mathrm{T}}$. Isolated from pig manure.

\section{ACKNOWLEDGEMENTS}

The authors wish to acknowledge the excellent technical assistance of Rhonda Zeltwanger.

\section{REFERENCES}

Bryant, M. P. (1972). Commentary on the Hungate technique for culture of anaerobic bacteria. Amer J Clin Nutr 25, 1324-1328.

Collins, M. D., Lawson, P. A., Willems, A., Cordoba, J. J., FernandezGarayzabal, J., Garcia, P., Cai, J., Hippe, H. \& Farrow, J. A. E. (1994). The phylogeny of the genus Clostridium: proposal of five new genera and eleven new species combinations. Int J Syst Bacteriol 44, 812-826.

Cotta, M. A., Whitehead, T. R. \& Zeltwanger, R. L. (2003). Isolation, characterization and comparison of bacteria from swine faeces and manure storage pits. Environ Microbiol 5, 737-745.

Dehority, B. A. \& Grubb, J. A. (1976). Basal medium for the selective enumeration of rumen bacteria utilizing specific energy sources. Appl Environ Microbiol 32, 703-710.

Hespell, R. B., Wolf, R. \& Bothast, R. J. (1987). Fermentation of xylans by Butyrivibrio fibrisolvens and other ruminal bacteria. Appl Environ Microbiol 53, 2849-2853. 
Johnson, J. L. (1994). Similarity analysis of DNAs. In Methods for General and Molecular Bacteriology, pp. 655-682. Edited by P. Gerhardt, R. G. E. Murray, W. A. Wood \& N. R. Krieg. Washington, DC: American Society for Microbiology.

Kageyama, A., Benno, Y. \& Nakase, T. (1999). Phylogenetic and phenotypic evidence for the transfer of Eubacterium aerofaciens to the genus Collinsella as Collinsella aerofaciens gen. nov., comb. nov. Int J Syst Bacteriol 49, 557-565.

Leedle, J. A. Z. \& Hespell, R. B. (1980). Differential carbohydrate media and anaerobic replica plating techniques in delineating carbohydrate-utilizing subgroups in rumen bacterial populations. Appl Environ Microbiol 39, 709-719.

Leser, T. D., Amenuvor, J. Z., Jensen, T. K., Lindecrona, R. H., Boye, M. \& Møller, K. (2002). Culture-independent analysis of gut bacteria: the pig gastrointestinal tract microbiota revisited. Appl Environ Microbiol 68, 673-690.

Miller, D. N. (2001). Accumulation and composition of odorous compounds in feedlot soils under aerobic, fermentative, and anaerobic respiratory conditions. J Anim Sci 79, 2503-2512.

Nicholas, K. B., Nicholas, H. B., Jr \& Deerfield, D. W., II (1997). GeneDoc: analysis and visualization of genetic variation. EMBNEW News 4, 14.

Page, R. D. M. (1996). TREEVIEW: an application to display phylogenetic trees on personal computers. Comput Appl Biosci 12, 357-358.

Rasmussen, S. W. (1995). DNATools, a software package for DNA sequence analysis. Carlsberg Laboratory, Copenhagen.

Saitou, N. \& Nei, M. (1987). The neighbour-joining method: a new method for reconstructing phylogenetic trees. Mol Biol Evol 4, 406-425.
Spoelstra, S. F. (1980). Origin of objectionable odorous components in piggery wastes and the possibility of applying indicator components for studying odor development. Agric Environ 5, 241-260.

Stackebrandt, E. \& Goebel, B. M. (1994). Taxonomic note: a place for DNA-DNA reassociation and $16 \mathrm{~S}$ rRNA sequence analysis in the present species definition in bacteriology. Int J Syst Bacteriol 44, 846-849.

Whitehead, T. R. \& Cotta, M. A. (2000). Characterisation and comparison of microbial populations in swine faeces and manure storage pits by $16 \mathrm{~S}$ rDNA gene sequence analyses. Anaerobe 7 , 181-187.

Whitehead, T. R. \& Flint, H. J. (1995). Heterologous expression of an endoglucanase gene (endA) from the ruminal anaerobe Ruminococcus flavefaciens 17 in Streptococcus bovis and Streptococcus sanguis. FEMS Microbiol Lett 126, 165-169.

Willems, A. \& Collins, M. D. (1996). Phylogenetic relationships of the genera Acetobacterium and Eubacterium sensu stricto and reclassification of Eubacterium alactolyticum as Pseudoramibacter alactolyticus gen. nov., comb. nov. Int J Syst Bacteriol 46, 1083-1087.

Yasuhara, A. \& Fuwa, K. (1979). Volatile and odorous components in solid swine manure. Agric Biol Chem 43, 313-316.

Yasuhara, A., Fuwa, K. \& Jimbu, M. (1984). Identification of odorous compounds in fresh and rotten swine manure. Agric Biol Chem 48, 3001-3010.

Zahn, J. A., Hatfield, J. L., Do, Y. S., DiSpirito, A. A., Laird, D. A. \& Pfeiffer, R. L. (1997). Characterization of volatile organic emissions and wastes from a swine production facility. J Environ Qual 26, 1687-1696. 